\title{
Cytomegalovirus Proctitis in a Patient with Chronic Lymphocytic Leukemia on Ibrutinib Therapy: A Case Report
}

Yeshaswini Reddy ${ }^{1}$, Muhammad Baig ${ }^{2}$, Nikhil Kalva ${ }^{2}$, Srinivas Puli ${ }^{2}$, Sonu Dhillon ${ }^{2}$

1. Internal Medicine, University of Illinois College of Medicine at Peoria - OSF Saint Francis Medical Center, Peoria, USA 2. Gastroenterology, University of Illinois College of Medicine at Peoria - OSF Saint Francis Medical Center, Peoria, USA

Corresponding author: Yeshaswini Reddy, psyeshaswini@gmail.com

\begin{abstract}
Ibrutinib is a Bruton tyrosine kinase (BTK) inhibitor that has shown significant efficacy in patients with lymphoid carcinomas, mostly chronic lymphocytic leukemia (CLL). Cytomegalovirus (CMV) infection is not a common infectious complication associated with ibrutinib. To increase the clinical awareness about this rare entity, we present the first case of CMV proctitis in an immunocompromised host who was being treated with ibrutinib.
\end{abstract}

An 88-year old female with a history of CLL treated with ibrutinib presented with two days of painless hematochezia. Physical examination revealed cachexia and temporal wasting; bright red blood was observed on the digital rectal examination. A complete blood count demonstrated a significant decrease in hemoglobin from her baseline. Subsequent colonoscopy revealed a circumferential rectal ulcer; biopsy of the rectal ulcer was positive for $\mathrm{CMV}$ immunostain. The patient was treated with intravenous ganciclovir and later transitioned to valganciclovir for a total of 21 days of treatment. Her condition resolved, and she was found doing well at the follow-up visit.

Categories: Gastroenterology, Infectious Disease

Keywords: cmv proctitis, immunosuppression, ibrutinib

\section{Introduction}

Ibrutinib is used for the treatment of relapsed or refractory chronic lymphocytic leukemia (CLL) in patients who have failed other chemo-immunotherapies [1,2]. The target of ibrutinib is the Bruton tyrosine kinase (BTK), an enzyme that is crucial for B- and T-cell proliferation and survival [3]. However, ibrutinib has been associated with several opportunistic infections, especially in the first 6-12 months of initiation of therapy $[3,4]$. Cytomegalovirus (CMV) is an opportunistic infection of immunosuppressed hosts due to T-cell dysfunction that occurs due to chronic antigen stimulation in the setting of latent viral infection or

Received 03/27/2020

Review began $03 / 30 / 2020$ Review ended 04/15/2020 Published 04/26/2020

\section{(c) Copyright 2020}

Reddy et al. This is an open access article distributed under the terms of the Creative Commons Attribution License CC-BY 4.0., which permits unrestricted use, distribution, and reproduction in any medium, provided the original author and source are credited. underlying cancer [1,5-7]. Gastrointestinal (GI) CMV infection is more pronounced in this patient population and leads to increased overall morbidity and mortality $[6,8]$. The pathophysiology is due to altered cellular immunity with impaired B- and T-cell function leading to the reactivation of CMV virus [3,7,9]. Here we report the case of an elderly female patient who presented with acute hematochezia and was eventually diagnosed with CMV proctitis in the background of ibrutinib immunosuppressive therapy. This is the first case of CMV proctitis in an immunocompromised host who was being treated with ibrutinib.

\section{Case Presentation}

An 88-year-old Caucasian female presented to the emergency room with a two-day history of painless hematochezia with associated generalized fatigue and unintentional weight loss of 10 pounds. She denied any change in her bowel habits, abdominal or rectal pain, fever, nausea, or vomiting episodes. Her past medical history was significant for CLL being treated with oral ibrutinib $420 \mathrm{mg}$ daily. She was hemodynamically stable and physical examination revealed cachexia and temporal muscle wasting; bright red blood was observed on the digital rectal examination. At this point, our differential diagnosis included hemorrhage secondary to diverticulosis, colorectal angiodysplasias, or internal hemorrhoids.

The following investigations were normal or negative: basic metabolic panel, coagulation profile, urinalysis, and chest X-ray. A complete blood count showed a reduction in hemoglobin level to $8.1 \mathrm{~g} / \mathrm{dL}$ compared to a baseline of $11.5 \mathrm{~g} / \mathrm{dL}$. Further evaluation with colonoscopy revealed a circumferential, deep, and clean-based rectal ulcer in close proximity to the dentate line (Figure 1). The rest of the colorectal mucosa was noted to be unremarkable. Biopsy of the rectal ulcer showed superficial fragments of ulcerated granulation tissue with no definitive viral cytopathic changes on hematoxylin and eosin stain. However, CMV immunostain was positive (Figure 2). Serum polymerase chain reaction (PCR) to detect CMV DNA was negative for viremia. 


\section{Cureus}

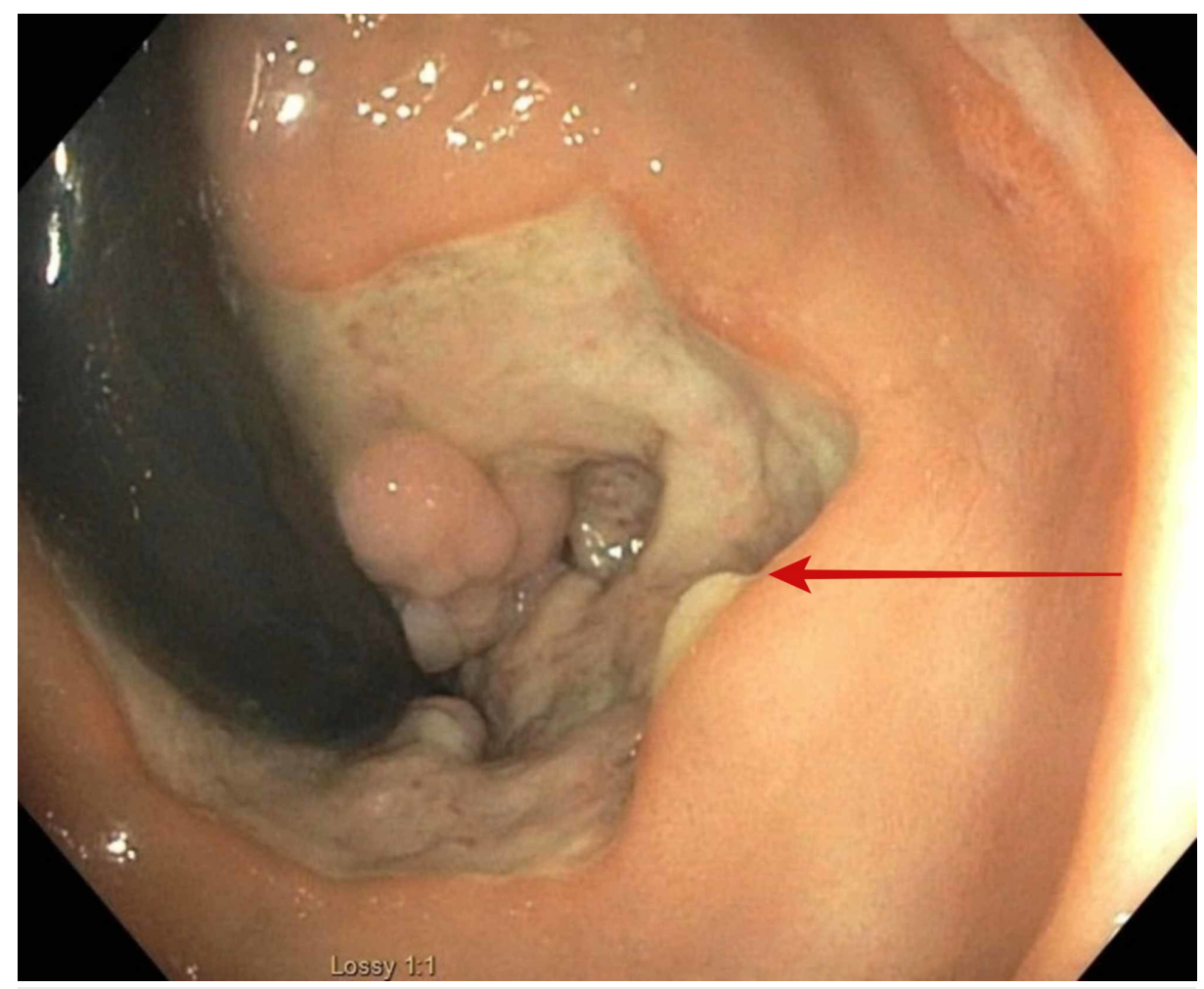

FIGURE 1: Retroflexed view of rectum showing a circumferential rectal ulcer (red arrow)

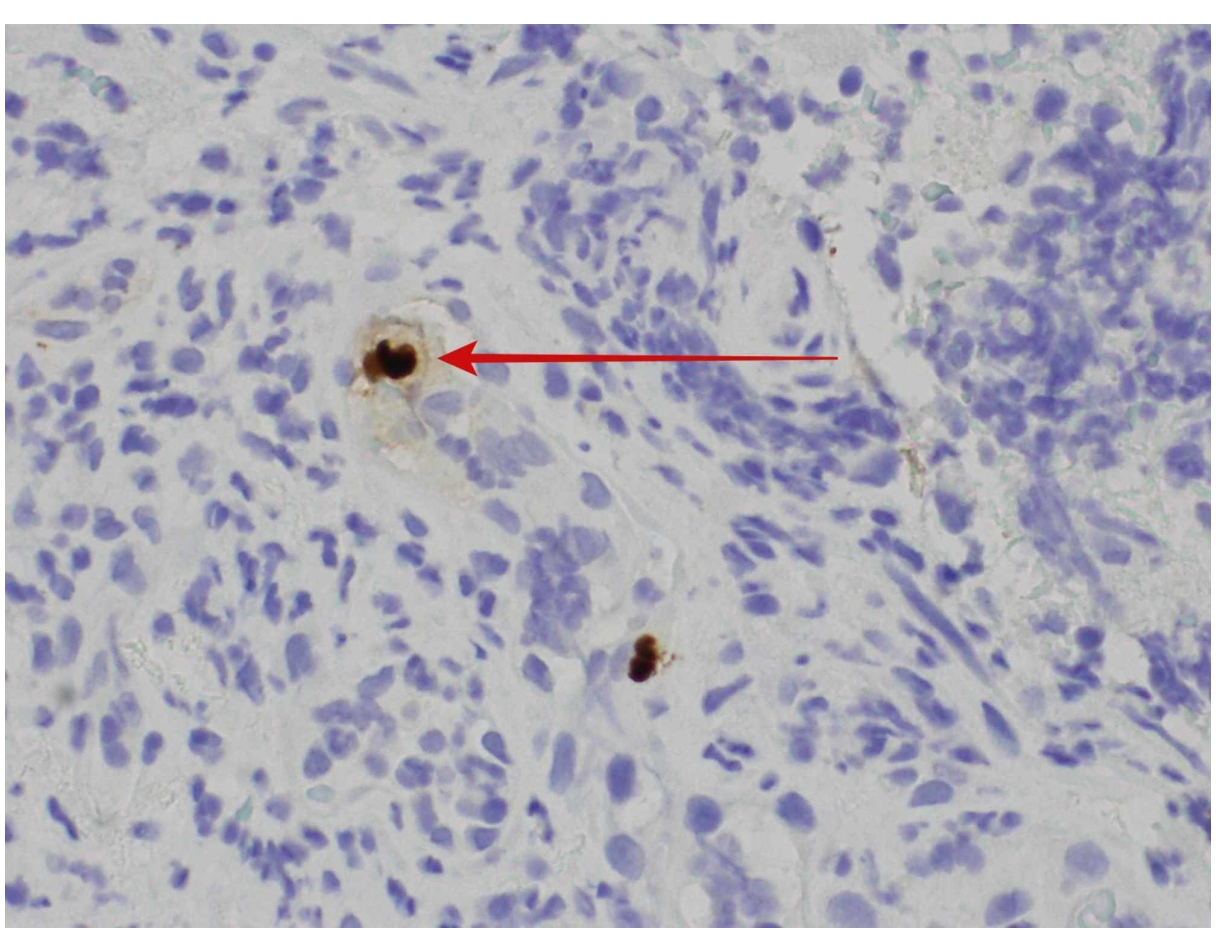

FIGURE 2: Immunostaining positive for CMV in the rectal ulcer with an illustration of an "owl eye inclusion" (red arrow)

CMV: cytomegalovirus

The patient was diagnosed with CMV proctitis secondary to immunodeficiency from ibrutinib treatment. She was initially started on intravenous ganciclovir $5 \mathrm{mg} / \mathrm{kg}$ twice daily for five days and then transitioned to 
oral valganciclovir $900 \mathrm{mg}$ twice daily for a total of 21 days of treatment. Her hematochezia gradually resolved in three days and she appeared to be doing well at her follow-up visit.

\section{Discussion}

Ibrutinib inhibits the BTK, which is an important signaling molecule in the pathogenesis of CLL, and has proven to suppress the B-cell lymphoproliferation and induce apoptosis of CLL cells [1,2]. Patients treated with BTK inhibitors are at increased risk of developing hypo-gammaglobulinemia due to the impairment of humoral immunity $[1,2,4]$. Several studies have also shown that ibrutinib decreases the regulatory T-cells by decreasing Th-2 cytokines in the cells during the first 6-12 months after initiation of therapy, thereby increasing the risk of opportunistic infections during this time period [10,11]. The most common infections associated with this drug are respiratory tract infections, followed by skin and ear infections [1,4].

CMV is a latent herpes virus infection that can undergo reactivation in an immunosuppressed host, leading to an increased risk of mortality and morbidity $[5,6,9]$. Therefore, early diagnosis and initiation of antiviral therapy are crucial for improved outcomes $[5,9,10]$. Patients with hematological neoplasms have impaired Tcell function, which increases their risk of CMV reactivation [9]. These patients, when started on immunosuppressant medications like ibrutinib, which alter the cellular immunity by further suppressing Band T-cell function, are at further increased risk for CMV infections [3,9]. In the GI tract, CMV infection may appear from mouth to anus, and tissue necrosis is noted to be a prominent feature [6,10]. Diagnosis is usually made by visualizing the large cells with intra-nuclear and intra-cytoplasmic inclusions as seen in our case. Despite the normal serological testing, colonoscopy and biopsies should be considered for diagnostic confirmation. Ibrutinib should be withheld in patients hospitalized with any infection and can be restarted once the infection is resolved. There are multiple drug interactions associated with ibrutinib therapy, and the literature does not support prophylactic antiviral therapy to prevent recurrent CMV infection [11].

\section{Conclusions}

CMV proctitis is an opportunistic infection that is commonly seen in immunosuppressed patients. These patients usually present with symptoms mimicking gastroenteritis or painless GI blood loss due to mucosal ulcerations. With the increasing utilization of immunosuppressive therapies like ibrutinib, CMV infections should be considered in the right clinical setting. Early diagnosis and treatment with appropriate antiviral therapy are critical for good outcomes. Further studies are required to investigate the benefits of empiric antiviral therapy in this patient population.

\section{Additional Information Disclosures}

Human subjects: Consent was obtained by all participants in this study. Conflicts of interest: In compliance with the ICMJE uniform disclosure form, all authors declare the following: Payment/services info: All authors have declared that no financial support was received from any organization for the submitted work. Financial relationships: All authors have declared that they have no financial relationships at present or within the previous three years with any organizations that might have an interest in the submitted work. Other relationships: All authors have declared that there are no other relationships or activities that could appear to have influenced the submitted work.

\section{References}

1. Parry HM, Mirajkar N, Cutmore N, et al.: Long-term ibrutinib therapy reverses CD8+ $\mathrm{T}$ cell exhaustion in B cell chronic lymphocytic leukemia. Front Immunol. 2019, 10:2832. Accessed: April 25, 2020: https://www.ncbi.nlm.nih.gov/pmc/articles/PMC6921985/. 10.3389/fimmu.2019.02832

2. Reinwald M, Silva JT, Mueller NJ, et al.: ESCMID Study Group for Infections in Compromised Hosts (ESGICH) consensus document on the safety of targeted and biological therapies: an infectious diseases perspective (intracellular signaling pathways: tyrosine kinase and mTOR inhibitors). Clin Microbiol Infect. 2018, 24:S53S70. 10.1016/j.cmi.2018.02.009

3. Varughese T, Taur Y, Cohen N, Palomba ML, Seo SK, Hohl TM, Redelman-Sidi G: Serious infections in patients receiving ibrutinib for treatment of lymphoid cancer. Clin Infect Dis. 2018, 67:687-692. 10.1093/cid/ciy175

4. Demitrovicova L, Mikuskova E, Oravcova I, Cingelova S, Drgona L, Mladosievicova B: Infectious complications in chronic lymphocytic leukemia- a retrospective analysis: single institution experience. Neoplasma. 2017, 64:474-481. 10.4149/neo_2017_320

5. Smith LA, Gangopadhyay M, Gaya DR: Catastrophic gastrointestinal complication of systemic immunosuppression. World J Gastroenterol. 2015, 21:2542-2545. 10.3748/wjg.v21.i8.2542

6. Sipponen T, Turunen U, Lautenschlager I, Nieminen U, Arola J, Halme L: Human herpesvirus 6 and cytomegalovirus in ileocolonic mucosa in inflammatory bowel disease. Scand J Gastroenterol. 2011, 46:1324-1333. 10.3109/00365521.2011.605466

7. Ahmed I, Kassem W, Salam Y, Furnari M, Mehta T: Outcome of cytomegalovirus colitis in inflammatory bowel disease with different regimes of ganciclovir. Middle East J Dig Dis. 2018, 10:220-229. 10.15171/mejdd.2018.114

8. Yan Z, Wang L, Dennis J, Doern C, Baker J, Park JY: Clinical significance of isolated cytomegalovirusinfected gastrointestinal cells. Int J Surg Pathol. 2014, 22:492-498. 10.1177/1066896914537681 


\section{Cureus}

9. Jain A, Prakash G, Khadwal A, Malhotra P, Bal A, Ahluwalia J, Varma S: Bloody diarrhea in a patient of aggressive lymphoma: a diagnostic and therapeutic challenge. Indian J Hematol Blood Transfus. 2017, 33:423-426. 10.1007/s12288-016-0748-X

10. Pillet S, Pozzetto B, Roblin X: Cytomegalovirus and ulcerative colitis: place of antiviral therapy . World J Gastroenterol. 2016, 22:2030-2045. 10.3748/wjg.v22.i6.2030

11. Brown JR: How I treat CLL patients with ibrutinib. Blood. 2018, 131:379-386. 10.1182/blood-2017-08764712 